On the basis of the papers, discussions, and recommendations arising from the workshops, a draft 'Biosphere Reserves Action Plan' was elaborated and adopted by the Congress. This document, which indicates what governments and international organizations should do to develop further the network of Biosphere Reserves and enhance their impact on conservation, science, and society, is being further elaborated by the Ecosystem Conservation Group - set up by the secretariats of FAO, UNEP, UNESCO, and IUCN-before submission to the forthcoming session of the intergovernmental coordinating council for the MAB Programme, which is expected to approve it formally. It is further expected that the Biosphere Reserves Action Plan will subsequently be endorsed by the governing bodies of the four international organizations concerned, thus giving it appropriate support at governmental level.*

A summary of the Congress proceedings will be published shortly by UNESCO in its MAB Reports series, and the full proceedings of the Congress will be published in English, French, Russian, and Spanish, as a joint UNESCO-UNEP publication.

It can be stated that the Minsk Congress fully achieved its objectives at the experts' level, and eloquently confirmed the special value of Biosphere Reserves as a new and flexible tool for environmental conservation and management which should be fully utilized all over the world. Further action for the implementation of the recommendations made in Minsk will be the responsibility of individual governments - with the assistance of the sponsoring international organizations, and the support of all those concerned with the conservation and rational use of ecosystems.

It should be added that the Congress was accompanied by an extremely important and well-presented exhibit displaying in particular the work carried out in the seven existing Biosphere Reserves in the Soviet Union, and the problems and achievements in land-use and conservation in Byelorussia. Congress participants had also the opportunity to visit the nearby Berezinsky Biosphere Reserve, with its museum, its special 'Nature School', its land-use experiments, and its comprehensive environmental monitoring equipment.

${ }^{*}$ It is understood that Environmental Conservation intends to publish this action plan as soon as possible after it has been approved.

Michel BATISSE, Assistant Director-General UNESCO, 7 place de Fontenoy 75700 Paris, France.

\section{World Meteorological Organization ExPERT Group Meeting on the Climatic Situation and DROUGHT IN AFRICA, HELD AT WMO HEADQUARTERS IN GENEVA, SWITZERLAND, DURING 6-7 OCTOBER 1983}

This meeting was held in response to a resolution of the Conference of Ministers of the Economic Commission for Africa (ECA) to organize a Scientific Roundtable on the climatic situation and drought in Africa. In preparation for the Roundtable (which is being held by ECA in Addis Ababa, Ethiopia, 20-23 February 1984), the WMO held a meeting on the climatic aspects of droughts, to be followed by a UNEP meeting on the impacts of drought on agriculture, water, land management, and other topics. The WMO meeting was chaired by Professor F. Kenneth Hare, Provost of Trinity College (University of Toronto, Canada) and Honorary Secretary of the Foundation for Environmental Conservation.

The Expert Group concluded that:

1) The drought in Africa which began in 1968 had not yet ended (in late 1983), despite near-normal rainfalls in the Sahel in 1974 and 1975. The drought which began in the Sahel in 1968 has, in recent years, spread to southern Africa and some parts of eastern Africa. Some countries in East Africa and in West Africa have had much less severe drought conditions during this latter period than from 1968-73.

2) The general meteorological causes of drought are well known but the specific quantitative conditions necessary for the onset and cessation of the African drought are not yet fully understood. One hypothesis states that mankind may be affecting the climate in Africa by changing the Earth's surface through overgrazing which affects the heat-balance, thereby producing downward atmospheric motions promoting drought. Further developments to explain the causal mechanisms can be expected in the next several years provided active research continues.

3) No useful periodicities or trends exist in the climate of Africa which cause or ameliorate drought. Although rainfall amounts in the Sub-Sahara have indeed markedly decreased over the past 15 years, there is no certainty that these deficiences will continue or will cease.

4) No known method exists to predict reliably the continuation, cessation, or recurrence, of drought in Africa.

5) Reliable and continuous weather data do not exist in many parts of Africa; these data are necessary to permit the analysis and warning of droughts.

6) Rain-making has not been convincingly demonstrated to be able to alleviate the current drought in Africa.

7) Drought is a common occurrence in many parts of the tropics and subtropics in Africa. Economies, in particular the agricultural sector, must be versatile enough to endure them.

8) Several positive actions can be taken by African countries to ensure better use than is currently made of existing climatic information, to improve the detection of drought, and to help alleviate its effects on agricultural production.

\section{The Expert Group recommended that:}

1) All African nations should establish drought-control plans, which would include positive actions to be taken that will help to detect drought and alleviate its effects on agricultural production.

2) National Meteorological Services in Africa, with the assistance of the WMO, should take prompt action to ensure that:

a) The necessary meteorological data are observed regularly and disseminated promptly to the operational and research communities, special emphasis being placed on necessary observations of rainfall, the upper atmosphere, and hydrological values;

b) The necessary data are available to detect and warn governments of impending drought conditions; and 
c) Meteorological services provide necessary support to the agricultural sector.

3) African governments should take prompt action to provide necessary resources to their National Meteorological Services.

4) Reliance should not be placed at this time on operational rain-making as a means of ameliorating conditions of drought.

THOMAS D. PoTTER, Director
World Climate Programme Department
World Meteorological Organization
41 Avenue Giuseppe-Motta
Case postale No. 5
1211 Geneva 20
Switzerland.

INTERNATIONAL WORKSHOP ON ENERGY CONSERVATION IN DEVELOPING COUNTRIES, HELD IN THE Palais des Nations, Geneva, Switzerland, DURING 21-25 NOVEMBER 1983

Sponsored by the United Nations Environment Programme (UNEP), an international group of experts was especially convened to discuss the important issue of energy conservation in developing countries.* While per caput energy consumption in developing countries is much lower than that in developed countries, it is generally agreed that, even then, the potential for energy conservation in developing countries is still significant. But whereas much discussion has taken place on energy conservation in developed countries, this was one of the very few international meetings where the problem was reviewed purely from the viewpoint of Third World countries.

The workshop had a draft report on the subject available for review, which had been prepared by Dr Yehia El Mahgary of the UNEP Secretariat. The 113pages' draft report was divided into six chapters: Introduction, Experience on Energy Conservation in Developed Countries, Experience on Energy Conservation in Developing Countries, Potential for Energy Conservation in Developing Countries, Economic and Environmental Aspects of Energy Conservation, and Guidelines for Energy Conservation in Developing Countries. The report also contained a comprehensive set of references on various aspects of the subject.

In the workshop, energy conservation was defined as including measures leading to increased socio-economic benefits per unit of energy spent.

This could be:

1) Energy saved in carrying out pre-planned activities by changing the operating style of the commodities (e.g. adjusting the thermostat in office buildings, driving at a slower speed than normally, optimizing the operation of power-plants, etc.).

2) Energy saved in carrying out pre-planned activities in the same, or better-than-formerly, fashion while at the same time reducing energy consumption and improv- ing environmental quality through good housekeeping measures and improved maintenance (e.g. continuous maintenance of vehicle engines, improving boiler efficiency, etc.).

3) Energy saved in carrying out pre-planned activities in the same or better fashion while, at the same time, reducing energy consumption and the environmental impacts, through replacing old items or adding new, efficient ones to increase the efficacity of energy-use (e.g. more efficient automobile engines, lowering domestic energy consumption through new or additional house installations, changing a condensing turbine into an extraction one for combined heat- and power-generation, etc.).

In reviewing energy savings in the major energyintensive industries in developing countries, it was noted that the potential for energy conservation varied from a high of $20-25 \%$ in the pulp and paper industry to a low of $5-10 \%$ in the aluminium, copper, or steel, industries. These estimates relate to existing production plants. For the domestic sector, when food is cooked over an open fire, only about $5-10 \%$ of its energy content is typically used, but by improving the existing stoves, fuelwood requirements could be reduced by half. Thus by improving the stoves used, not only could energy be saved but also deforestation could be reduced. The major constraints to energy conservation were clearly identified in the draft report.

The key actions were to be found in integrating energy conservation in the whole development plan of a country, rationalizing the use of energy sources, supporting these efforts by adequate legislative and institutional frameworks, providing energy users with energy pricing strategies to eliminate energy waste, allocating funds for investment and incentive in energy efficiency improvements, and establishing educational/promotional programmes and information systems for increasing the awareness of the relevance and importance of energy conservation.

Probably the most important part of the draft report was the Guidelines prepared for specific sector-wise conservation measures. The sectors considered were industry, buildings and residential, transport, and electric power. The final report will be available shortly.

The Energy Programme of UNEP* has always been one of its most successful ones. It is a pleasure to see that the UNEP Secretariat, with only one professional staff member in the area of energy, can not only look after all the existing projects but can also prepare excellent, comprehensive reports-an example which other international agencies should try to emulate.

\section{Asit K. Biswas, President \\ International Society for Ecological Modelling \\ 76 Woodstock Close \\ Oxford $O X 28 D D$ \\ England, $U K$.}

\footnotetext{
* See also the brief notice on page 361 of our preceding issue.-
} Ed.

For an 'Important Prospect', please turn to page 94. 